\section{Operation Moonshot: Leaked documents prompt questions over cost, evidence, and reliance on private sector}

\begin{abstract}
The UK government's plans to carry out up to 10 million covid-19 tests a day by early next year as part of a $f 100$ bn expansion of its national testing programme raise many questions Gareth lacobucci examines the leaked documents
\end{abstract}

\section{Gareth lacobucci}

\section{What is Operation Moonshot?}

It refers to the government's plan to deliver a mass population testing programme for covid-19 by early 2021, with the aim to test the whole UK population each week. A confidential briefing memo sent to Scotland's first minister and cabinet secretaries, seen by The BMJ, ${ }^{1}$ reveals plans to grow the UK's testing capacity from the current 350 ooo a day to up to 10 million tests a day by early 2021, costing "over £1oobn to deliver.” The plans are dependent on a huge upscaling in diagnostic capacity and the use of as yet unvalidated technologies. They envisage a prominent role for the private sector in planning and delivery.

\section{What is the government's desired outcome?}

The government's aim is to "utilise the full range of testing approaches and technologies to help reduce the $\mathrm{R}$ rate, keep the economy open and enable a return to normal life." The Whitehall memo makes it clear that the prime minister views mass testing as the UK's "only hope for avoiding a second national lockdown before a vaccine, something the country cannot afford." He would also like this to support the opening up of the economy and allow the population to return to something closer to normality. Many suspect that the desire for positive headlines is also driving this particular agenda and the eye catching numbers behind it.

\section{How does the plan differ from the current testing strategy?}

The current government advice is that only people with symptoms should have a covid-19 test. The Moonshot strategy moves way beyond this, stating that the plan is to eventually test the whole population, including people without symptoms "where testing enables economic or other vital activity and builds societal confidence." But with the current test and trace system still struggling to operate effectively, and people still being asked to travel hundreds of kilometres to get a standard polymerase chain reaction (PCR) swab test, there are concerns that the government is running before it can walk. Chris Ham, former chief executive of the King's Fund, said, "I wish the government were much more focused on getting our current system working effectively, particularly given the increases in positive cases, because we are at a very critical moment now."

\section{Where does the $£ 100 \mathrm{bn}$ figure come from?}

The documents do not explain how the government calculated the f1oobn cost. Ministers have refused to be drawn on the figure since The BMJ first published the details on 9 September but have not denied that it was used in internal correspondence. To put the number in context, €10obn is almost an entire year's budget for the NHS in England (£13obn) and more than double the UK’s annual entire defence budget ( $£ 41 \mathrm{bn})$. The documents say that the government's Scientific Advisory Group for Emergencies (SAGE) is modelling the potential effect of a mass testing programme on the R number, while the Treasury is doing the same for the economy. Nigel Edwards, chief executive of the Nuffield Trust, said he was stunned by the figure being quoted, which he said could fund 150 new NHS hospitals. "It seems an astonishingly large amount of money to be talked about without a proper assessment of the costs and benefits," he said.

\section{Who is spearheading the strategy?}

A PowerPoint presentation prepared for the government by the global management consulting firm Boston Consulting Group, seen by The BMJ, reveals a heavy reliance on the accountancy and consultancy firm Deloitte to manage and oversee the plans, alongside other firms such as PA Consulting. ${ }^{2}$ The presentation is packed with jargon heavy flow diagrams and metaphorical references such as "Moonshot Headquarters" and "Mission HQ." The lack of clinical and system-wide input has drawn criticism from experts. Martin McKee, professor of European public health at the London School of Hygiene and Tropical Medicine, said, "This is yet another standalone initiative, developed without any apparent involvement of those on the ground or acknowledgement of existing structures. Worse, it envisages a major role for Deloitte, a company that has presided over many of these problems." Since the start of the pandemic Deloitte has played a prominent role in building and managing logistics at drive-through testing facilities and in introducing home testing. But it faced criticism back in April after reports that GPs were left without access to many thousands of their patients' covid-19 test results carried out at the centres. 


\section{How does the UK plan to scale up capacity?}

The documents show that the plan is to effectively build a new diagnostics industry to achieve the huge increase in capacity. They indicate that "letters of comfort are already in place with companies to reach 3 million tests per day by December." Potential partners listed include drug companies such as GSK on the supply side, AstraZeneca for increasing laboratory capacity, and Boots, Sainsbury's, DHL, Kuehne+Nagel, G4S, and Serco for logistics and warehousing (box 1). Some experts have expressed alarm at the sums of public money that could be channelled into contracts with private firms. Anthony Costello, a former director of maternal and child health of the World Health Organization and professor at University College London, described the plans as "waste/corruption on a cosmic scale.”

Box 1: Operation Moonshot's list of "strategic partners"

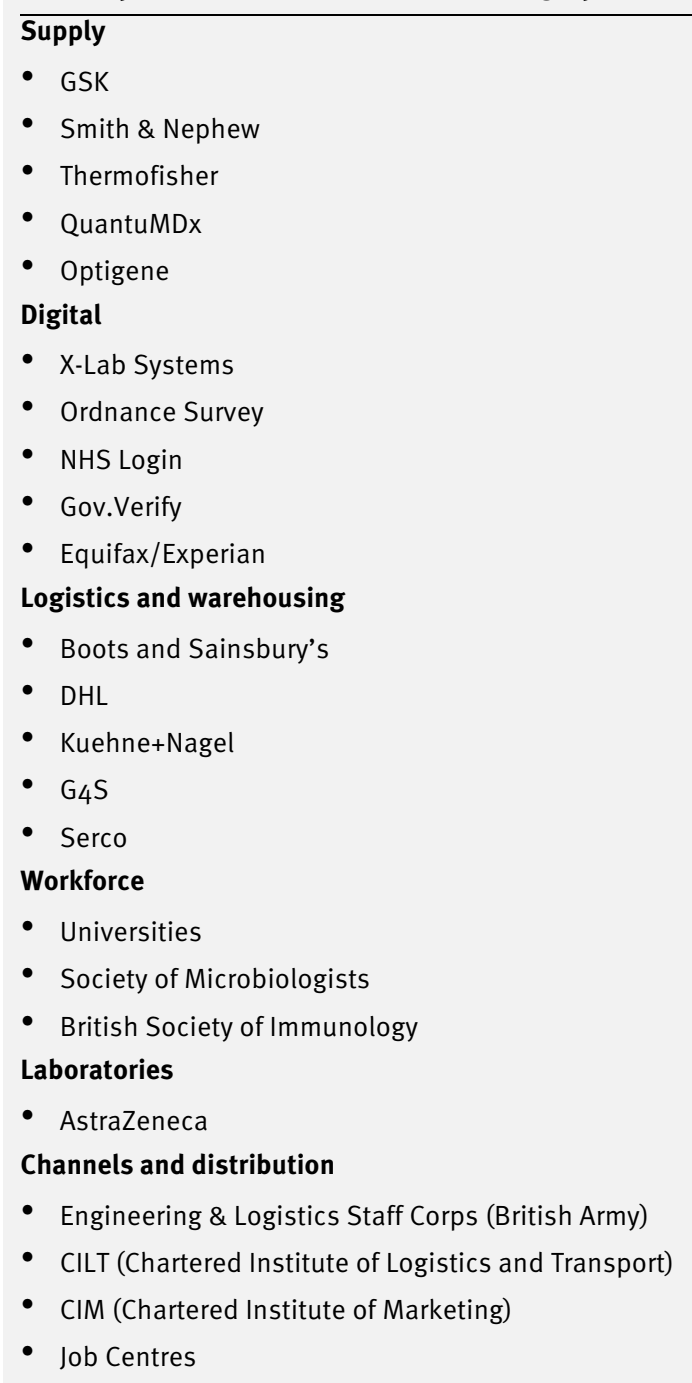

\section{How will the government find the workforce to deliver this?}

The documents state that the government will work with universities, the Society of Microbiologists, and the British Society of Immunology to try to grow the diagnostic workforce. There are also plans to offer covid-19 tests at general practices and pharmacies to boost access, as part of what the government calls a "huge new operational infrastructure." 3 The documents say, "This will include a new warehousing and an expanded logistics network, and a new workforce with the appropriate skills and expertise to deliver, administer and process our new testing technology in every corner of the UK." But there is little detail, and Edwards said that recruitment on this scale at the pace being talked about sounded "deeply implausible," given the time required to recruit and train people. "If half of the cost is on testing and the other half is on staff (as it is in the NHS), we could be talking about employing 1.6 million people," he said.

\section{What are other countries doing?}

Countries such as China and South Korea initially deployed testing on a wide scale to try to reduce the spread of covid-19, and the US and India are now testing widely. Denmark, with a population of six million, announced on 18 May that it would begin offering mass population testing, including to people without symptoms. ${ }^{4}$ And France has also tried population testing. But none of these countries have rolled out mass testing on the same whole population scale as the UK is proposing. Devi Sridhar, professor and chair of global public health at the University of Edinburgh, points out that a commitment to wider testing can cause problems if testing capacity then becomes 
stretched. "We don't want to make the same mistakes as France, where there is broader testing being offered and it is being used by lots of 'worried well' people, leading to queues and delays in results," she said.

\section{What is the evidence for mass testing?}

Experts are concerned that the Moonshot plans seem to have had little involvement by scientists, clinicians, or experts in screening. Jon Deeks, professor of biostatistics at the University of Birmingham and leader of the Cochrane Collaboration's covid-19 test evaluation activities, said, "The document lacks insight into how screening works, particularly the need to balance the harms you can create through false positives against the benefits from true positives.” The concern about false positives is particularly pertinent given that the plans rely on as yet unvalidated tests. Deeks warned of a "risk of this backfiring." He said, "Even if you have a test which is $99 \%$ specific, so only $1 \%$ of uninfected people get a false positive result, if you then test 60 million people we will be classifying a group the size of the population of Sheffield as wrongly having covid." If these people and their close contacts had to isolate, this, Deeks noted, would create "substantial economic harm and massive need for further testing."

\section{What does SAGE say?}

In a consensus statement dated 31 August SAGE struck a cautious note about mass testing. ${ }^{5}$ It said, "Careful consideration should be given to ensure that any mass testing programme provides additional benefit over investing equivalent resources into improving the speed and coverage of NHS Test and Trace for symptomatic cases ... and the rate of self-isolation and quarantine for those that test positive." It noted that the cheaper, faster tests that will be useful for mass testing will yield more false positives, and it added that "mass testing can only lead to decreased transmission if individuals with a positive test rapidly undertake effective isolation."

\section{Is the plan achievable?}

The document itself acknowledges that "much of what we are trying to do is unprecedented around the world," indicating just how ambitious the plan is and how challenging it will be to deliver. Experts are highly sceptical. Edwards said, "My strong suspicion is that this will end up like the airports on the island or the bridge [promised for London by Boris Johnson when he was mayor of London but not delivered]. Quite a lot of effort will be expended on it, but I will be quite surprised if it survives a more rigorous look at the economics." McKee was equally sceptical, saying the plans bore the hallmark of a government "whose ambition far exceeds its ability to deliver." He added, "This plan transmits unbounded optimism, disregarding the enormous problems with the existing testing and tracing programmes."

Table 1 | Moonshot's "mission analysis" from the leaked documents

\begin{tabular}{|c|c|c|c|}
\hline Mission & Objective & Test setting & Geography \\
\hline $\begin{array}{l}\text { Mass test general population to contain spread } \\
\text { and build societal confidence }\end{array}$ & Pilot LAMP testing in Greater Manchester & Train stations; additional settings to be agreed & Salford \\
\hline $\begin{array}{l}\text { Test asymptomatic NHS employees regularly } \\
\text { to ensure NHS can operate effectively }\end{array}$ & $\begin{array}{l}\text { Deliver a pilot for asymptomatic testing in NHS } \\
\text { and other settings; } \\
\text { build body of evidence }\end{array}$ & Hospitals; laboratories (Lighthouse, NHS) & Southampton, Basingstoke, Manchester \\
\hline \multirow{3}{*}{$\begin{array}{l}\text { Test target institutions (such as schools and } \\
\text { universities) regularly using a risk based model } \\
\text { to enable safe return to normal life }\end{array}$} & a) Lateral flow testing & Schools or universities (TBC) & UK \\
\hline & b) Cohort pooling & Schools (TBC) & UK \\
\hline & c) ePCR & TBC & UK \\
\hline $\begin{array}{l}\text { Develop an agile and comprehensive testing } \\
\text { capability, beyond current approach, to identify } \\
\text { and contain outbreaks }\end{array}$ & $\begin{array}{l}\text { Develop use of mobile and quick turnaround } \\
\text { technologies }\end{array}$ & $\begin{array}{l}\text { Closed institutions; open institutions; } \\
\text { community gatherings and local community }\end{array}$ & UK \\
\hline $\begin{array}{l}\text { Enable private sector organisations to deliver } \\
\text { testing safely and effectively, including to } \\
\text { facilitate economic activity or protect their } \\
\text { workforces }\end{array}$ & TBC & Employers; point of entry to venues & UK \\
\hline
\end{tabular}

\footnotetext{
lacobucci G, Coombes R. Covid-19: Government plans to spend f100bn on expanding testing to 10 million a day. BMJ2020;370:m3520. doi: 10.1136/bmj.m3520 pmid: 32907851

2 lacobucci G. Covid-19: GPs can't get results of tests carried out at drive-through centres. BMJ2020;369:m1875.pmid: 32393500

3 Mahase E. Operation Moonshot: GP clinics could be used to improve access to covid-19 tests. BMJ2020;370:m3552. doi: 10.1136/bmj.m3552 pmid: 32912858

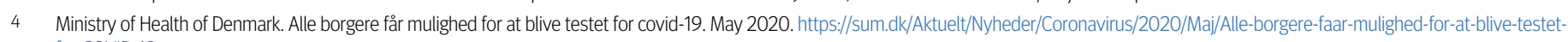
for-COVID-19.aspx.

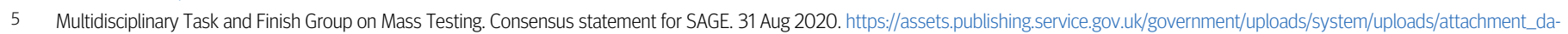
ta/file/914931/s0712-tfms-consensus-statement-sage.pdf.
}

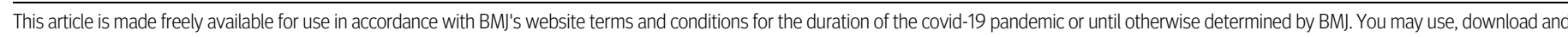
print the article for any lawful, non-commercial purpose (including text and data mining) provided that all copyright notices and trade marks are retained. 